\title{
Prevalence of Metabolic Syndrome among Border Guard Bangladesh Personnel
}

\author{
Wahab MA ${ }^{1}$, Rahman $\mathrm{MM}^{2}$, Razzak $\mathrm{MA}^{3}$, Rahman $\mathrm{MH}^{4}$, Parvin $\mathrm{M}^{5}$, Zafreen $\mathrm{F}^{6}$ \\ DOI: https://doi.org/10.3329/jafmc.v14i2.45883
}

\begin{abstract}
Introduction: Metabolic syndrome (MetS) is a multifaceted syndrome comprises a cluster of metabolic abnormalities including hypertension, central obesity, insulin resistance, dyslipidemia, and is strongly associated with developing diabetes mellitus and cardiovascular diseases. Prevalence of MetS differs in different ethnic population by using different definition.
\end{abstract}

Objectives: To determine the prevalence of the MetS and its component risk factors among Border Guard Bangladesh (BGB) personnel working in Chattagram Hill Tract (CHT).

Materials \& Methods: This descriptive cross-sectional study was conducted from October 2016 to February 2018 among 1455 male BGB personnel aged between 40 to 59 years and working in $\mathrm{CHT}$ of Bangladesh. Study subjects were selected at BGB hospital, Guimara, Khagrachari. The new International Diabetes Federation (IDF) guidelines were used to identify MetS. Detail history, clinical examination, anthropometry and blood pressure (BP) were measured and fasting plasma glucose (FPG) and lipid profile were assessed.

Results: Among the 1455 respondents'BMI, waistcircumference, systolic and diastolic BP were found more than normal in $34.1,37.7,16.4 \%$ and $12.3 \%$ respectively. Biochemical parameters including FPG, TC, TG, and LDL-C was raised in $28.7 \%, 49.8 \%, 52.2 \%$ and $37.7 \%$ of respondents respectively. HDL-C was found decreased in $26.9 \%$ respondents. Age wise prevalence of MetS for age group 40-44, 45-49, 50-54 and 5559 years were found $21.3 \%, 21.7 \%, 24.1 \%$ and $26.1 \%$ of the respondents respectively. The overall prevalence of MetS was found $22.4 \%$.

Conclusion: The prevalence of the MetS in BGB personnel was found $22.4 \%$. Appropriate measure should be taken to lower the MetS cases.

Key-words: Metabolic syndrome, International diabetic federation, Border guard Bangladesh.

\section{Introduction}

The Metabolic Syndrome (MetS) is a constellation of an interconnected physiological, biochemical, clinical, and metabolicfactorsthatdirectlyincreases the risk ofatherosclerotic cardiovascular disease (CVD) and Type 2 Diabetes Mellitus $(\mathrm{DM})^{1-3}$. The concept of MetS was first introduced in 1988 by Gerald Reaven ${ }^{4}$. The diabetes consultation group of the World Health Organization (WHO) created the first internationally recognized definition of MetS in 19985. They defined MetS as the presence of insulin resistance (impaired fasting glucose, impaired glucose tolerance, or type 2 diabetes mellitus) in addition to two of the following risk factors: obesity by waisthip ratio or body mass index (BMI), dyslipidemia, hypertension or microalbuminuria ${ }^{1,5}$.

MetS is now considered as a global epidemic ${ }^{6}$, with current estimates of International Diabetes Federation (IDF) ${ }^{7}$ estimates that one-quarter of the world's adult population has the MetS. The prevalence of MetS based on National Cholesterol Education Program modified Adult Treatment Panel III (NCEP/ ATPIII) ${ }^{8}$ criteria, 2001 varied from $8 \%$ to $43 \%$ in men and from $7 \%$ to $56 \%$ in women around the world. The prevalence of MetS among South Asians, a community that represents one-fifth of the global population is on the rising trend $d^{9,10}$. The prevalence rates of MetS were reported to be higher than $40 \%$ in India ${ }^{11}$. Higher socioeconomic status, sedentary lifestyle, and high BMI were significantly associated with MetS ${ }^{12}$. Very few studies have done to find the prevalence of MetS in Bangladesh. Two studies conducted in Bangladesh and prevalence of MetS was $20.7 \%$ in total population ${ }^{13}$ and $31.25 \%$ among menopausal women ${ }^{14}$. To find out the prevalence of the MetS and its components among BGB personnel, working in Chattagram Hill Tract (CHT) of Bangladesh.

\section{Materials and Methods}

This descriptive cross-sectional study was conducted from October 2016 to February 2018 among 1455 male BGB personnel aged between 40 to 59 years and working in $\mathrm{CHT}$ of Bangladesh. Study subjects were selected at BGB hospital, Guimara, Khagrachari from the BGB personnel who came for biannual health check-up under newly introduced 'Health

1. Lt Col Md Abdul Wahab, MBBS, MD, Associate Professor of Biochemistry, Armed Forces Medical College (AFMC), Dhaka (E-mail: wahab947@ gmail.com) 2. Maj Gen Md Mustafizur Rahman, MBBS, MPH, MBA, FCGP, Ex-Commandant, AFMC, Dhaka 3. Brig Gen Md Abdur Razzak, MBBS, MCPS, FCPS, APLAR Clinical Fellow Rheumatology, Professor and Head, Department of Medicine, AFMC, Dhaka 4. Brig Gen Md Habibur Rahman, MBBS, FCPS, Professor of Medicine, AFMC, Dhaka 5. Brig Gen Mimi Parvin, MBBS, DCP, MCPS, FCPS, Professor \& Head, Department of Biochemistry, AFMC, Dhaka 6. Dr Farzana Zafreen, MBBS, MPH, Associate Professor \& Head, Department of Community Medicine, Medical College for Women \& Hospital, Uttara, Dhaka. 
Card' project. New IDF7 guidelines were used to identify MetS. Detail history, clinical examination, anthropometry and blood pressure (BP) were measured. Laboratory investigations like fasting plasma glucose (FPG) and lipid profile including total cholesterol (TC), triglyceride (TG), high density lipoprotein cholesterol (HDL-C) and low density lipoprotein cholesterol (LDL-C) were assessed to all the subjects.

Anthropometric measurements including weight, height, and waist circumference of the participants were measured in standing position with minimum clothing and without shoes. Height was measured with a wall-mounted meter scale nearest to 0.5 centimeter $(\mathrm{cm})$ and the weight was taken to the nearest $0.1 \mathrm{~kg}$ by calibrated digital bathroom scale. Waist circumference was measured at the minimum circumference between the lower border of ribs and iliac crest on the mid axillary line by a measuring tape and the measurement was taken nearest to $0.5 \mathrm{~cm}$. BMI was calculated by standard formula as [weight in $\mathrm{Kg} /\left(\right.$ height in $\mathrm{m}^{2}$ ]. BP was recorded in sitting position, in the right arm to the nearest $2 \mathrm{~mm}$ of $\mathrm{Hg}$ using the mercury sphygmomanometer. Two readings were taken in ten minutes apart and their average value was taken as BP. After overnight (8-10 hours) fasting blood samples were taken to estimate the FPG and serum lipid proflie. TC, TG, and HDL-C, were measured by auto analyzer and LDL-C was calculated using the Friedewald formula ${ }^{15}$. All the collected data were assembled in a pre-structured checklist and analyzed by using SPSS-21.0 for Windows. The categorical data were expressed in frequency and percentage and for statistical significance $\chi^{2}$ test was done and $p<0.05$ considered as significance.

Diagnosis of MetS: Diagnosis of MetS was performed on the basis of new IDF diagnostic criteria ${ }^{7}$. According to 2005 IDF definition for a person to be defined as having the MetS must have central obesity with ethnicity specific values for different groups16. We use waist circumference (WC) $\geq 90 \mathrm{~cm}$ in men which is recommended for South Asian countries plus any two or more of the following four factors:

- Raised TG levels $\geq 150 \mathrm{mg} / \mathrm{dl}$ or specific treatment for this lipid abnormality

- Reduced HDL-C < 40mg/dl in men or specific treatment for this lipid abnormality

- Raised blood pressure: Systolic BP $\geq 130 \mathrm{~mm}$ of $\mathrm{Hg}$ or diastolic $\mathrm{BP} \geq 85 \mathrm{~mm}$ of $\mathrm{Hg}$ or treatment of previously diagnosed hypertension and

- Raised fasting blood glucose $>5.6 \mathrm{mmol} / \mathrm{L}$ or previously diagnosed diabetes mellitus.

\section{Results}

Respondents socio-demographic characteristics presented in table-I. BMI, WC, systolic and diastolic BP were more than normal in $34.1,37.7,16.4 \%$ and $12.3 \%$ of respondents respectively (Table-II). Respondents' biochemical parameters found FPG, TC, TG, and LDL-C was raised in $28.7 \%, 49.8 \%$, $57.2 \%$ and $37.7 \%$ of respondents respectively. HDL-C was found decreased in $26.9 \%$ respondents (Table-III). Prevalence of DM (FPG $\geq 7.0 \mathrm{mmol} / \mathrm{L}$ ) was $7.5 \%$. Age wise prevalence of MetS for age group 40-44, 45-49, 50-54 and 55-59 years were found $21.3 \%, 21.7 \%, 24.1 \%$ and $26.1 \%$ of the respondents respectively. Age wise prevalence of MetS found increasing trends with age but was not statistically significant $(p>0.05)$. The overall prevalence of MetS was found $22.4 \%$ according to IDF criteria (Table-IV).

Table-I: Socio-demographic characteristics of respondents $(n=1455)$

\begin{tabular}{|l|l|r|r|}
\hline \multicolumn{2}{|c|}{ Characteristics } & Frequency & Percentage \\
\hline \multirow{4}{*}{ Age group } & $40-44$ & 554 & 38.1 \\
\cline { 2 - 4 } & $45-49$ & 457 & 31.4 \\
\cline { 2 - 4 } & $50-54$ & 348 & 23.9 \\
\cline { 2 - 4 } & $55-59$ & 96 & 6.6 \\
\hline \multirow{4}{*}{ Rank } & JCO & 143 & 9.8 \\
\cline { 2 - 4 } & $\mathrm{NCO}$ & 1079 & 74.2 \\
\cline { 2 - 4 } & Sepoy & 144 & 9.9 \\
\cline { 2 - 4 } & Civilian & 89 & 6.1 \\
\hline \multirow{3}{*}{ Monthly family income (BDT) } & $\mathrm{A}$ & 1314 & 90.3 \\
\cline { 2 - 4 } & $\mathrm{B}$ & 54 & 3.7 \\
\cline { 2 - 4 } & $\mathrm{C}$ & 87 & 6.0 \\
\cline { 2 - 4 } & $<200000$ & 113 & 7.8 \\
\cline { 2 - 4 } & $>40000$ & 245 & 75.4 \\
\hline
\end{tabular}

Table-II: Distribution of respondents by BP, waist circumference and BMI $(n=1455)$

\begin{tabular}{|c|c|c|c|c|}
\hline \multicolumn{3}{|c|}{ Biochemical parameters } & Frequency & Percentage \\
\hline \multirow{4}{*}{$\begin{array}{l}\mathrm{BP} \\
\text { in } \mathrm{mm} \\
\text { of } \mathrm{Hg}\end{array}$} & \multirow{2}{*}{ Systolic } & $<130$ & 1217 & 83.6 \\
\hline & & $\geq 130$ & 238 & 16.4 \\
\hline & \multirow{2}{*}{ Diastolic } & $<85$ & 1276 & 87.7 \\
\hline & & $\geq 85$ & 179 & 12.3 \\
\hline \multirow{2}{*}{\multicolumn{2}{|c|}{ BMI (kg/m2) }} & $<25$ & 959 & 65.9 \\
\hline & & $\geq 25$ & 496 & 34.1 \\
\hline \multirow{2}{*}{\multicolumn{2}{|c|}{ Waist Circumference $(\mathrm{cm})$}} & $<90$ & 906 & 62.3 \\
\hline & & $\geq 90$ & 549 & 37.7 \\
\hline
\end{tabular}

Table-III: Biochemical parameters of respondents $(n=1455)$

\begin{tabular}{|l|c|c|c|}
\hline \multicolumn{2}{|c|}{ Biochemical parameters } & Frequency & Percentage \\
\hline \multirow{3}{*}{ Fasting plasma glucose (mmol/L) } & $<5.6$ & 1038 & 71.3 \\
\cline { 2 - 4 } & $\geq 5.6$ & 417 & 28.7 \\
\cline { 2 - 4 } & $\geq 7.0$ & 109 & 7.5 \\
\hline \multirow{2}{*}{ Total Cholesterol (mg/dl) } & $<200$ & 730 & 50.2 \\
\cline { 2 - 4 } & $\geq 200$ & 725 & 49.8 \\
\hline \multirow{2}{*}{ Triglyceride (mg/dl) } & $<150$ & 623 & 42.8 \\
\cline { 2 - 4 } & $\geq 150$ & 832 & 57.2 \\
\hline \multirow{2}{*}{ LDL Cholesterol (mg/dl) } & $<130$ & 906 & 62.3 \\
\cline { 2 - 4 } & $\geq 130$ & 549 & 37.7 \\
\hline \multirow{2}{*}{ HDL Cholesterol (mg/dl) } & $<40$ & 391 & 26.9 \\
\cline { 2 - 4 } & $\geq 40$ & 1064 & 73.1 \\
\hline
\end{tabular}


Table-IV: Age stratified prevalence of metabolic syndrome $(n=326)$

\begin{tabular}{|c|c|c|c|c|}
\hline \multirow{2}{*}{ Age group in years } & \multirow{2}{*}{ Total Population } & \multicolumn{2}{|c|}{ Prevalence of MetS } & \multirow[t]{2}{*}{ Statistics } \\
\hline & & Yes n (\%) & No $n(\%)$ & \\
\hline $40-44$ & 554 & 118 (21.3) & 436 (78.7) & \multirow{5}{*}{$\begin{array}{c}x^{2}=1.866 \\
d f=3 \\
p>0.05\end{array}$} \\
\hline $45-49$ & 457 & $99(21.7)$ & 358 (78.3) & \\
\hline $50-54$ & 348 & $84(24.1)$ & $264(75,9)$ & \\
\hline $55-59$ & 96 & $25(26.0)$ & $71(74.0)$ & \\
\hline Total & 1455 & $326(22.4)$ & $1129(77.6)$ & \\
\hline
\end{tabular}

\section{Discussion}

In this study among the dyslipidemia high serum TG levels was found to be the most common component of MetS which was observed in $57.2 \%$ followed by high TC, which was found $49.8 \%$ of the target population. This observation in our target population is critical considering that epidemiological studies $^{9,10}$ have established a strong association between high TG concentrations with increased risk of CVD. But other studies found low HDL-C is the most common dyslipidemia ${ }^{17,18}$. This difference might be due to different food habit and regular exercise of target population. The overall prevalence of hypertension in this target population was $16.4 \%$ which was lower than previously reported Meta analysis ${ }^{18}$ of 61 prospective studies in which prevalence of hypertension was $18.2 \%$. This study showed prevalence of raised FPG was $28.7 \%$ respondents among them $7.5 \%$ had diabetes mellitus. This finding was also lower than the other similar study ${ }^{17}$ and the reason might be the same.

The overall prevalence of MetS by new IDF criteria was $22.4 \%$ among the BGB personnel working in $\mathrm{CHT}$ of Bangladesh. The prevalence increased with age in our population. The prevalence rate was relatively lower than that of other South Asian studies where prevalence rates of MetS showed 35.2\% to $41 \%$ in this subcontinent ${ }^{9,10}$. An Indian urban study showed high prevalence of MetS (41.1\%) using the modified ATPIII criteria $^{19}$. A study conducted in Pakistan aged 40 years and above showed a prevalence rate of MetS $45.9 \%$ in males and $57.2 \%$ in females ${ }^{20}$. A cross sectional study ${ }^{17}$ on newly diagnosed diabetes mellitus subjects from BIRDEM hospital has shown the prevalence of MetS $39.6 \%$. This difference among different studies might be due to using different criteria for diagnosis of MetS and different group of population and geographical region. Prevalence of MetS in this study was lower than similar studies in home and abroad that might be due to that this study was performed on a special group of population. BGB members have to strict discipline in their life including regular physical activities.

Result of this study found lower prevalence of MetS in target BGB population by which might be because of their disciplined lifestyle, mandatory participation in physical exercise and games, taking healthy balanced diet and overall strict supervision for preventing over weight. As the population was specific group of population so it may not represent the prevalence of MetS of Bangladesh.

\section{Conclusion}

The prevalence of MetS in BGB personnel working in CHT of Bangladesh was found $22.4 \%$ by new IDF criteria. The burden of non communicable disease such as CVD and DM in our region is increasing as a consequence of higher MetS in this population. Appropriate measure should be taken to lower the emerging threat of MetS cases by adopting effective health care and preventive program.

\section{References}

1. Rochlani Y, Pothineni NV, Kovelamudi S et al. Metabolic syndrome: Pathophysiology, management, and modulation by natural compounds. Therapeutic advances in cardiovascular disease. 2017; 11(8):215-25.

2. Grundy SM, Cleeman JI, Daniels SR, Donato KA, Eckel RH, Franklin BA, Gordon DJ, Krauss RM, Savage PJ, Smith Jr SC, Spertus JA. Diagnosis and management of the metabolic syndrome: An American Heart Association/National Heart, Lung, and Blood Institute scientific statement. Circulation 2005; 112(17):2735-52.

3. Reaven GM. Banting lecture role of insulin resistance in human disease. Diabetes. 1988; 37:1595-607.

4. Wilson PW, D'Agostino RB, Parise $\mathrm{H}$ et al. Metabolic syndrome as a precursor of cardiovascular disease and type 2 diabetes mellitus. Circulation. 2005; 112(20):3066-72.

5. Grundy SM, Hansen B, Smith Jr SC et al. Clinical Management of Metabolic Syndrome: Report of the American Heart Association/National Heart, Lung, and Blood Institute/American Diabetes Association Conference on Scientific Issues Related to Management. Arteriosclerosis Thrombosis and Vascular Biology 2004; 24(2):e19-24.

6. Hildrum B, Mykletun A, Hole T et al. Age-specific prevalence of the MS defined by the IDF and national cholesterol education program: the Norwegian HUNT 2 study. BMC Public Health 2007; 7:220.

7. International Diabetes Federation: The IDF consensus worldwide definition of the metabolic syndrome. Available at http://www.idf.org/ metabolic-syndrome.

8. Cleeman JI. Executive summary of the third report of the National Cholesterol Education Program (NCEP) expert panel on detection, evaluation, and treatment of high blood cholesterol in adults (adult treatment panel III) Journal of the American Medical Association. 2001; 285(19):2486-97.

9. Eaoeb D, Jakra GL, Nercgabt $N$ et al. Metabolic syndrome and cardiovascular disease in south Asians. Vase Health Risk Manage.2009; 5:731-43.

10. Gupta M, Singh N, Verma S. South Asians and cardiovascular risk what clinicians should know. Circulation 2006; 113:924-9.

11. Magat G, Govel NK, Walia DK, et al. Metabolic syndrome: A challenging health issue in highly urbanized union territory of north India. Diabetic Metabolic Syndrome 2010; 2:19.

12. Ramachandran A, Snehaltha C, Satyavani K et al. Metabolic Syndrome in Urban Asian Indian adults-A population study using modified ATP III criteria. Diab Res Clin Pract 2003; 60:199-204. 
13. Rahim MA, Khan AKAA, Sayeed MA et al. Metabolic Syndrome in rural Bangladesh: Comparison of newly proposed IDF, modified ATP III and WHO criteria and their agreements. Diabetes and metabolic syndrome: Clinical research and Reviews 2007; 1:251-7.

14. Jesmin S, Mia S, Islam AM et al. Prevalence of metabolic syndrome rural Bangladeshi women. Diabetes Res Clin Pract 2012; 95(1):e7-9.

15. Friedewald WT, Levy RI, Fredrickson DS. Estimation of the concentration of low-density lipoprotein cholesterol in plasma without use of the preparative ultracentrifuge. Clin Chem 1972; 18:399-402.

16. Alberti KGMM, Zimmet P, Shaw J. Metabolic syndrome-A new world wide definition. A consensus statement from the International Diabetes Federation. Diabet Med 2006; 23:469-80.
17. Uk khan, Dipta TF, Mofaruque et al. Prevalence of Metabolic Syndrome in Diabetic Patient. J Bangladesh College of Physician and surgeons 2012; 30:85-90.

18. Lewington MS, Whitlock $G$, Clarke R et al. Blood cholesterol and vascular mortality by age, sex, and blood pressure a meta-analysis of individual data from 61 prospective studies with 55,000 vascular deaths. Lancet 2007; 370:1829-39.

19. Ramachandran A, Senhalatha C, Satyvani K, et al. Metabolic syndrome in urban Asian Indian adults-a population studies using modified ATP III criteria. Diabetes Res Clin Pract 2003; 60:199-204.

20. Wierzbzbicki, AS, Nishtar S, Lumb PJ et al. Metabolic Syndrome and risk of coronary heart disease in a Pakistan cohort. Heart 2005; 91:1003-7. 